\title{
Climate change may threaten the southernmost Pinus nigra subsp. salzmannii (Dunal) Franco populations: an ensemble niche-based approach
}

\author{
Rafael M Navarro-Cerrillo ${ }^{(1)}$, \\ Joaquín Duque-Lazo ${ }^{(1)}$, \\ Rubén D Manzanedo ${ }^{(2)}$, \\ Raúl Sánchez-Salguero ${ }^{(3)}$, \\ Guillermo Palacios-Rodriguez ${ }^{(1)}$
}

\section{Introduction}

Tree species distribution is mainly determined by climate and soil (i.e., ecological drivers), despite the effect of historical factors such as the presence of glacial refuges (Svenning \& Skov 2007) and the naturaliza-

\begin{abstract}
We used Species Distribution Modeling to predict the probability of Iberian pine (Pinus nigra subsp. salzmannii [Dunal] Franco) occurrences in southern Spain in response to environmental variables and to forecast the effects of climate change on their predicted geographical distribution. The ensemble modeling approach "biomod2" was used, together with present lberian pine data, to predict the current potential distribution based on bioclimatic explanatory variables ( $200 \mathrm{~m}$ resolution) and to forecast future suitability by studying three periods $(2040,2070$, and 2100), considering the Global Circulation Models $B C M 2$, CNCM3, and ECHAM5, and the regional model EGMAM, for different scenarios (SRAB1, SRA2, SRB1). Model evaluation was performed using Kappa, True Skills Statistic (TSS), and Area Under the Curve (AUC) values. The biomod2 approach highlighted the average number of days with a minimum temperature equal to or below $0^{\circ} \mathrm{C}$, annual precipitation, and aridity index as the most important variables to describe the $P$. nigra occurrence probability. Model performances were generally satisfactory and the highest AUC values and high stability of the results were given by GAM and GLM, but MaxEnt and the SRE model were scarcely accurate according to all our statistics. The ensemble Species Distribution Modeling of $P$. nigra in Andalusia predicted the highest probability of species occurrence in the eastern areas, Sierra de $\mathrm{Ca}$ zorla being the area with the highest occurrence of $P$. nigra in Andalusia. In the future habitat, the general probability of $P$. nigra occurrence in Andalusia will decrease widely; the species is expected to lose habitat suitability at moderate altitudes and its occurrence probability will have decreased by nearly $70 \%$ on average by 2100 , affected by the selected scenario. Populations in Sierra de Cazorla are those most suitable for $P$. nigra growth, even under the most pessimistic scenarios. It is likely that the natural southern populations of $P$. nigra will be very sensitive to changes in climate.
\end{abstract}

Keywords: Species Distribution Modeling, Climate Change, Ensemble Modeling, Iberian Pine, Mediterranean Relict Forests tion of species beyond their former range (Pyšek et al. 2014). Projected trends in the context of global change suggest an increase in the mean annual temperatures, drought, and frequency of extreme events in the Mediterranean Basin. Understanding $\square$ (1) Department of Forestry, School of Agriculture and Forestry, University of Córdoba, Edf. Leonardo da Vinci, Campus de Rabanales s/n, Mail Box 3048, E-14071 Córdoba (Spain); (2) Institute of Plant Sciences, University of Bern, Altenbergrain 21, CH-3013 Bern (Switzerland); (3) Area de Ecología, Dpto. Sistemas Físicos, Químicos y Naturales, Universidad Pablo de Olavide, Ctra. Utrera km. 1, E-41013 Sevilla (Spain)

@ Rafael M Navarro-Cerrillo (rmnavarro@uco.es)

Received: Aug 07, 2017 - Accepted: Mar 10, 2018

Citation: Navarro-Cerrillo RM, Duque-Lazo J, Manzanedo RD, Sánchez-Salguero R, PalaciosRodriguez G (2018). Climate change may threaten the southernmost Pinus nigra subsp. salzmannii (Dunal) Franco populations: an ensemble niche-based approach. iForest 11: 396405. - doi: 10.3832/ifor2588-011 [online 2018-05-15]

Communicated by: Francesco Ripullone the effects of climate on tree distribution is particularly relevant in relict drought-prone forests; for example, those of southern Iberia (Benito Garzón et al. 2008), which are considered to be highly exposed to climate change, in which both warming and aridification trends have been observed (Giorgi 2006). These recent trends had negative effects on the tree growth (SanchezSalguero et al. 2012), forest productivity (Madrigal-González \& Zavala 2014), and distribution of the southernmost Iberian coniferous forests (Benito Garzón et al. 2008). An improved understanding of the responses to climate of the distribution of relict circum-Mediterranean pine populations provides a valuable system for investigating the role played by ongoing warming at the southern distribution limit of these species, where they usually face severe drought stress.

The Iberian pine (Pinus nigra Arn. subsp. salzmannii [Dunal] Franco - hereafter abbreviated as $P$. nigra subsp. salzmannii) is widely distributed in the western Mediter- 
ranean area, ranging from the large populations in the eastern Pyrenees Mountains to the southernmost isolated populations in southeastern Spain and northern Morocco. At the southernmost edge of their distribution, Iberian pine populations are fragmented and located in the high mountains of the Baetic Range (Camarero et al. 2013), which makes them especially vulnerable to climate change effects (Camarero et al. 2013, Navarro-Cerrillo et al. 2014). In Andalusia (in the south of the Iberian Peninsula), native high-mountain tree species like $P$. nigra subsp. salzmannii used to cover large areas (Elena-Rosselló \& Sánchez-Palomares 1991). However, as a result of historical forest harvesting, pruning, and grazing over hundreds of years, most of the natural stands are heavily degraded, remaining as isolated relict populations (Elena-Rosselló \& Sánchez-Palomares 1991).

Nowadays, forest harvesting has been reduced but the main risk faced by these populations is climate change. Previous studies have shown that black pine is sensitive to an increase in temperature and decrease in precipitation (Sanchez-Salguero et al. 2012, Navarro-Cerrillo et al. 2014). In this area, the forecasted climate trends indicate a notable reduction in annual precipitation (3-20\%), an increase in mean temperature $\left(0.3-1.5^{\circ} \mathrm{C}\right.$ per decade), and an increase in the frequency, duration, and intensity of droughts.

Species Distribution Modeling (SDM) forecasts the probability of species occurrences in response to environmental variables, and could predict the future habitat suitability of species under climate change scenarios (Elith \& Franklin 2013). However, SDM faces several methodological issues that may affect the prediction of the above habitat suitability - such as the choice of the model's algorithm (Merow et al. 2014), the selection of environmental variables (Mod et al. 2016) or background points used for the model's calibration, and the conversion of occurrence probabilities into presence and absence estimates (Vale et al. 2014). However, careful implementations of SDM have demonstrated the usefulness of the models with regard to predicting the habitat suitability of a given species. Moreover, multiple studies have compared the accuracy and performance of such models for Mediterranean tree species (Badeau et al. 2010, Navarro-Cerrillo et al. 2011, Attorre et al. 2011, Bede-Fazekas et al. 2014, Marchi et al. 2016), although no superiority of any single one has been proved (Merow et al. 2014). Araújo \& New (2007) underlined the benefit of ensemble models over single models. The former combine the results of several independent models, which surpass the influence of a single algorithm in model predictions, and this is expected to balance the accuracy and robustness of the models (Zhang et al. 2015). Many studies using SDM have been carried out in the Iberian Peninsula (García-Valdés et al. 2013, López-Tirado \& Hidalgo 2014), and a few have modeled the changes in habitat suitability of $P$. nigra subsp. salzmannii and its future distribution in the Iberian Peninsula (Felicísimo et al. 2011, López-Tirado \& Hidalgo 2014), but the use of ensemble SDM approaches might improve the accuracy of biodiversity conservation and management policies in relict forests (Porfirio et al. 2014). For P. nigra subsp. salzmannii, it is at the edge of its distribution and in the highest mountains where we can expect the strongest response to purely climatic conditions. Likewise, the relict $P$. nigra subsp. salzmannii populations at the southernmost edge of the current distribution represent an important genetic reservoir for the future conservation of the species under increasing drought and aridity (Soto et al. 2010). The genetic characteristics of P. nigra subsp. salzmannii might help to conserve the species at higher latitudes, even in areas where it already occurs but is not genetically adapted to the forecasted change in climate conditions (Herrero et al. 2013, López-Tirado \& Hidalgo 2014). Moreover, in situ conservation and biodiversity management require information on plant species distribution at a local scale (Van Gils et al. 2012).

The modeling of the distribution of endangered species, like $P$. nigra subsp. salzmannii, is especially challenging because of the lack of data and the high level of human disturbance in some of the populations (Elith \& Franklin 2013). In this paper, we have used ensemble SDM of habitat to explore current and future impacts of climate change on relict populations of Iberian pine in the southern Iberian Peninsula. We used the biomod2 R-package (Thuiller et al. 2013), which combines 10 different model algorithms and calculates a final ensemble prediction. We aimed to identify the major environmental variables explaining black pine climate suitability in the southernmost Iberian forests, and then to explore the potential responses of the species to predicted changes in climate using three intercontinental Global Circulation Models and one regional model, for three different scenarios, at a very fine scale (200 meters resolution). In addition, we discuss whether the factors driving the occurrence of this tree species in the southern Iberian Peninsula are similar to those reported previously for other Iberian relict regions.

\section{Material and methods}

\section{Study areas}

The study areas are located in Andalusia, southern Spain, a characteristic region of the Mediterranean Basin located in the south of the Iberian Peninsula (Fig. S1 in Supplementary material). The climate in this region is typically Mediterranean, with hot and dry summers and precipitation concentrated in spring and autumn. Forests of P. nigra subsp. salzmannii are lo- cated in the highest forested range of the Baetic mountains, characterized by great topographical variability and a high degree of natural disturbances, including wild fires and, often, non-sustainable forest management. Andalusia contains most of the natural stands of Iberian pine in its southernmost populations, with the exception of those located in Morocco and Algeria (Camarero et al. 2013). The natural P. nigra subsp. salzmannii forests in eastern Andalusia are dominant in north-oriented and high-elevation sites (1500-2270 m a.s.l.) and occupy ca. 107,000 ha. There are also extensive plantations (ca. 40,000 ha) of P. nigra subsp. salzmannii, which were mostly planted in mid to high-elevation sites (1200$2150 \mathrm{~m}$ a.s.I.) between the 1960 s and 1970 . We did not consider these plantations in this study because they may be established outside their bioclimatic range (López-Tirado \& Hidalgo 2014).

\section{Location data and environmental variables}

Information on species occurrences and bioclimatic variables was compiled from the Andalusian Regional Government database (REDIAM 2010). We used 977 presence records (points) of natural $P$. nigra subsp. salzmannii forests from the third $\mathrm{Na}$ tional Spanish Forest Inventory (Villanueva 2005). We selected the presence records within natural populations because natural P. nigra subsp. salzmannii stands presented a more plastic response to climate change and more severe decline have been associated to planted trees (Sanchez-Salguero et al. 2013), which suggest that some of P. nigra subsp. salzmannii plantations might be outside of its bioclimatic range. An equal number of pseudo-absences (Prevalence equal to 0.50) with 10 replicates (BarbetMassin et al. 2012) within the study area were generated using the biomod2 $\mathrm{R}$ package (Thuiller et al. 2013).

The climate data consisted of 29 environmental variables (Tab. S1 in Supplementary material) averaged for the period 19602000 and the future predictions were carried out for three periods: 2011-2040; 20412070, and 2071-2099, following regional scenarios (REDIAM 2010). For each period, we considered three intercontinental Global Circulation Models ( $\mathrm{BCM} 2, \mathrm{CNCM}_{3}$, and ECHAM5) and one regional model (EGMAM), developed in the project Climate Change Scenarios updated in the $4^{\text {th }}$ IPCC report, as well as three climate change scenarios ( $A 1 B, A 2$, and $B 1-I P C C$ 2014), to take into account a high variability in future projections. The complete dataset had a spatial resolution of 200-meter grids. In all our analyses, we used average period values.

\section{Variable reduction and importance}

The initial 29 environmental variables were reduced by the variable inflation factor (VIF<10 - Quinn \& Keough 2002), principal component analysis (PCA), and the relative quality of the statistical models mea- 
sured by Akaike's Information Criterion (AIC) values. We took the non-collinear variables as the means of the first two principal components (Franklin 2010), and from those we selected the final variables based on their importance in predicting the climate suitability, as judged by AIC.

Variable importance was quantified using the Variable Importance function within biomod2, which is implemented by calculating the Pearson's correlation ( $r$ ) between model predictions including all remaining variables (a "full model") and predictions excluding the variable being tested (a "reduced model"). If a variable has a low contribution to a model, the two outputs would be similar, and (1-r) would be low, while the opposite would be the case for important variables (Thuiller et al. 2013). This variable importance procedure does not allow the comparison of importance between models. Therefore, we used the ranking system described in Syphard \& Franklin (2009) to compare variable selection between model types.

\section{Statistical models}

To deal with model selection, we used ensemble models from 10 SDM algorithms (Thuiller et al. 2013), employing the biomod2 package ( $R$ Core Development Team 2014). This package allows one to perform ensemble SDM using presence-absence data that includes: Generalized Linear Models (GLM), Generalized Additive Models (GAM), Classification and Regression Trees (CART), Flexible Discriminate Analysis (FDA), Artificial Neural Networks (ANN), Multivariate Adaptive Regression Splines (MARS), Maximum Entropy Modelling (MaxEnt), Random Forest (RF) and Boosted Regression Trees (BRT) and one similar to BIOCLIM, Surface Range Envelop (SRE).

We used ensemble models calculated using the mean, median, coefficient of variation, upper and lower confidence interval, committee averaging and probability mean weight decay of the single model predic- tions (Thuiller et al. 2013).

The consensus methods employed in this study make up a representative sample of the most commonly used techniques. Four methods (Median, Mean, Coefficient of Variation, and Confidence Intervals) are based on their statistical functions, whereas the Probability Mean Weight Decay (WD) and Committee Averaging (CA) methods preselect the single models based on certain predefined criteria. In WD, half of the single-model outputs are preselected on the basis of the True Skills Statistic (TSS) values. The selected single models are combined using an averaging function. In CA the probabilities of the selected models are first converted into binary, according to the maximal TSS threshold, and the CA score is calculated as the average of the binary predictions (Thuiller et al. 2013).

\section{Model calibration and validation}

We randomly divided our dataset into two subsets, which we used to train the model ( $70 \%$ of the data) and to evaluate it independently (the remaining 30\%). This yielded 100 different fits per model, each with its own accuracy indicator, mean, and quantiles of model accuracy calculated. Models with higher mean values and smaller variations were considered as being the most accurate ones (Duque-Lazo et al. 2016).

Model performance was evaluated by the AUC of the Receiver Operating Characteristic plot, Kappa, and TSS. The AUC represents the models' discriminative capacity with regard to the data and is obtained by plotting the commission error (1-specificity; false positives) on the horizontal axis, versus the omission error (sensitivity; actual positives which are correctly identified as such) on the vertical axis, for numerous thresholds. The AUC ranges between o (= opposite prediction) and 1 (= perfect prediction) with $0.5=$ random, where 1 represents a perfect discrimination between presence and absence and 0.5 represents a random fit. As an evaluation metric, AUC has the advantage of being prevalence and threshold independent (Franklin 2010).

Cohen's Kappa ( $\mathrm{k}$ ) was derived from the 2 $\times 2$ confusion matrix to measure the rate of agreement between actual and predicted values in the spatial space for categorical Kappa values; however, the matrix depends on the defined threshold for presence. Values of $k$ near to 0.5 indicate no discrimination capacity (random agreement), whereas a value of 1 represents the perfect discrimination model (Cohen 1960). The TSS is concerned with omission and commission errors and is also prevalence independent. It ranges from -1 to +1 , where +1 indicates perfect agreement and $<0$ indicates a random performance. The TSS measures the difference between the actual agreement and the randomly expected agreement; it is particularly useful for the modeling of rare species with limited point locations and it can be used to compare different modeling techniques. The TSS is defined as (Allouche et al. 2006 - eqn. 1):

$T S S=$ sensitivity + specificity -1

Finally, Kappa and TSS were calculated and evaluated, considering a threshold equal to prevalence (Vale et al. 2014).

\section{Distribution maps}

We generated continuous probabilistic maps with values of between 0 and 1 for each grid point, for the present and future habitat distributions of $P$. nigra subsp. salzmannii in Andalusia. In order to assist the visual interpretation of the model predictions, the probability values were classified into four categories (0-25\%; $25-50 \%$; $50-75 \%$; $75-100 \%$ ). To calculate the shifts in the range of the surface area from the present to the future distributions, we reclassified the probabilities as o (unsuitable habitat) and 1 (suitable habitat); the methods used to estimate the threshold were the same as those employed to calculate TSS and
Fig. 1 - Response curve of the ensemble model Committee Averaging for the explanatory variables: average reference evapotranspiration (ETO), aridity index (IAR), average num-

ber of days with a minimum temperature equal to or below $0^{\circ} \mathrm{C}$ (NDF), annual precipitation (PRE), annual sum of the positive differences between precipitation and reference evapotranspiration (SSUP), and average snow precipitation (SNOW)
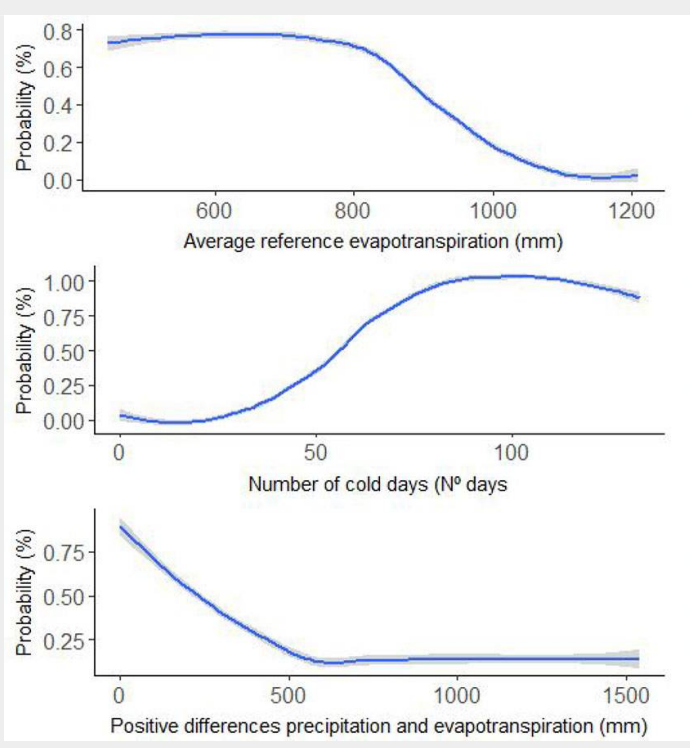
Kappa. Finally, we focused on six different relict areas (Andalusia, Sierra Cazorla, Sierra María, Sierra de Baza, Sierra Nevada, and Sierra de las Nieves - Fig. 1) to evaluate the effect of climate change on each population.

\section{Results}

\section{Variable reduction}

The results of the variable selection highlighted that 17 predictors out of 29 were affected by collinearity problems $(\mathrm{VIF}<10)$, of which eight were selected with high correlations with the first two principal components of the PCA and six were highlighted by AIC model selection. The final set of the six variables selected included the: average reference evapotranspiration (ETO); aridity index (IAR); average number of days with a minimum temperature equal to or below $0{ }^{\circ} \mathrm{C}$ (NDF); annual precipitation (PRC); annual sum of the positive differences between precipitation and reference evapo- transpiration (SSUP); and average snow precipitation (SNOW - Tab. 1). Moreover, the biomod2 ranked classification of variable importance (Tab. 2) highlighted NDF as the most important variable, followed by PRC and IAR. The single scorings of variable importance from the separate model techniques generally agreed with this classification, reinforcing our variable selection (Tab. 2).

Our results show that the probability of $P$. nigra subsp. salzmannii occurrence increases with PRC and NDF, while it decreases with increases in ETO and SSUP. We also observed slight responses to aridity and snow cover (Fig. 1). Locations with low annual precipitation (PRC $<915 \mathrm{~mm}$ ) or high transpiration losses (ETO $>908 \mathrm{~mm}$ or SSUP > $719 \mathrm{~mm}$ ) were highly unsuitable for $P$. nigra subsp. salzmannii growth. Surprisingly, we observed a weak response to aridity; low aridity values maximized the occurrence probability but the response was otherwise rather flat. Similarly, snow cover did not significantly affect the occurrence probability (Fig. 1).

\section{Model selection and validation}

The single model predictions were compared by their accuracy as given by TSS, Kappa, and AUC; overall, these showed good model accuracy (Fig. 2). The model performances were generally satisfactory and the highest AUC values and lowest variances were shown by GAM and GLM, although they had lower TSS and Kappa values than ANN, BRT, and RF, which were also highly accurate. Although CART, FDA, and MARS possessed low predictive power and stability, they exhibited high (CART) or moderate (FDA and MARS) correlation with other models. However, the MaxEnt and SRE models were scarcely accurate according to all our statistics (Fig. 2). The bivariate Pearson correlation analysis highlighted the low correlation of the MaxEnt and SRE predictions with those of the rest of the model techniques used. On the

Tab. 1 - Variable importance ranking and parametric characterization of $P$. nigra subsp. salzmannii for 1000 runs and 10 habitat prediction model techniques. Variable abbreviation is indicated in parentheses. (QtI): quartile.

\begin{tabular}{|c|c|c|c|c|c|c|c|}
\hline Rank & Variable & Min & $1^{\text {st }} Q$ tl & Mean & $3^{\text {rd }} Q \mathrm{tl}$ & $\operatorname{Max}$ & Units \\
\hline 1 & $\begin{array}{l}\text { Average number of days with a minimum temperature equal to or } \\
\text { below } 0{ }^{\circ} \mathrm{C} \text { (NDF) }\end{array}$ & 35.30 & 65.40 & 76.30 & 90.00 & 158.90 & days \\
\hline 2 & Annual precipitation (PRC) & 306.00 & 558.00 & 760.00 & 919.00 & 1513.00 & $\mathrm{~mm}$ \\
\hline 3 & Aridity index (IAR) & 35.00 & 94.00 & 116.00 & 160.00 & 296.00 & - \\
\hline 4 & $\begin{array}{l}\text { Annual sum of the positive differences between precipitation and } \\
\text { reference evapotranspiration (SSUP) }\end{array}$ & 1.00 & 142.00 & 312.00 & 453.00 & 1046.00 & $\mathrm{~mm}$ \\
\hline 5 & Average reference evapotranspiration (ETO) & 92.00 & 840.00 & 891.00 & 934.00 & 1087.00 & $\mathrm{~mm}$ \\
\hline 6 & Average snow precipitation (SNOW) & 27.00 & 134.00 & 266.00 & 446.00 & 1170.00 & $\mathrm{~mm}$ \\
\hline- & Aspect (ASPECT) & -453.00 & -27.00 & 8.00 & 49.00 & 333.00 & degree \\
\hline- & Sum of water balances at the end of each month $(\mathrm{BH})$ & 1.00 & 685.00 & 1894.00 & 3011.00 & 7707.00 & $\mathrm{~mm}$ \\
\hline- & Digital elevation model (DEM) & 7.00 & 1164.00 & 1423.00 & 1705.00 & 2995.00 & $\mathrm{~m}$ \\
\hline- & Average net primary production (DF) & 182.00 & 1223.00 & 1928.00 & 2471.00 & 3371.00 & hours \\
\hline- & $\begin{array}{l}\text { Average number of days with a maximum temperature equal to or } \\
\text { above } 35{ }^{\circ} \mathrm{C} \text { (NDC) }\end{array}$ & 0.10 & 5.70 & 10.20 & 16.20 & 44.40 & days \\
\hline- & Annual radiation $(\mathrm{RN})$ & 26.00 & 95.00 & 103.00 & 107.00 & 126.00 & Julian $\mathrm{m}^{-2}$ \\
\hline- & $\begin{array}{l}\text { Annual sum of the negative differences between precipitation and } \\
\text { reference evapotranspiration (SDEF) }\end{array}$ & 84.00 & 394.00 & 440.00 & 506.00 & 657.00 & $\mathrm{~mm}$ \\
\hline - & Slope (SLOPE) & 1.00 & 11.00 & 17.00 & 24.00 & 100.00 & $\%$ \\
\hline - & Average maximum temperature (T_MAX) & 12.20 & 16.60 & 17.60 & 18.60 & 22.20 & ${ }^{\circ} \mathrm{C}$ \\
\hline - & Average mean temperature (T_MED) & 4.10 & 10.20 & 11.20 & 12.20 & 15.60 & ${ }^{\circ} \mathrm{C}$ \\
\hline- & Average minimum temperature (T_MIN) & -4.50 & 3.70 & 5.00 & 6.10 & 9.50 & ${ }^{\circ} \mathrm{C}$ \\
\hline- & Maximum of the monthly average maximum temperatures (TMAXC) & 24.40 & 28.80 & 30.00 & 31.10 & 34.70 & ${ }^{\circ} \mathrm{C}$ \\
\hline- & Average maximum temperature of all months (TMC) & 14.30 & 20.20 & 21.20 & 22.50 & 26.00 & ${ }^{\circ} \mathrm{C}$ \\
\hline - & Average minimum temperature of all months (TMF) & -1.80 & 3.10 & 4.00 & 4.90 & 8.50 & ${ }^{\circ} \mathrm{C}$ \\
\hline - & Minimum of the monthly average minimum temperatures (TMINF) & -8.40 & -2.10 & -1.00 & -0.10 & 3.30 & ${ }^{\circ} \mathrm{C}$ \\
\hline
\end{tabular}

Tab. 2 - Mean variable importance values for 100 runs, for each selected variable and the habitat prediction model techniques. Generalized Linear Models (GLM), Generalized Additive Models (GAM), Classification and Regression Trees (CART), Flexible Discriminate Analysis (FDA), Artificial Neural Networks (ANN), Multivariate Adaptive Regression Splines (MARS), Maximum Entropy Modelling (MaxEnt), Random Forest (RF) and Boosted Regression Trees (BRT) and one similar to BIOCLIM, Surface Range Envelop (SRE). Variable description in Tab. 1. $(*): P<0.05 ;(*): P<0.01$.

\begin{tabular}{|c|c|c|c|c|c|c|c|c|c|c|}
\hline Variable & ANN & BRT & CART & FDA & GAM & GLM & MARS & MaxEnt & RF & SRE \\
\hline ETO & 0.19 & 0.02 & 0.03 & 0.06 & 0.30 & 0.18 & 0.28 & 0.01 & 0.03 & 0.31 \\
\hline IAR & 0.07 & 0.01 & 0.03 & 0.06 & 0.12 & 0.04 & 0.13 & 0.01 & 0.04 & 0.11 \\
\hline NDF & $0.73^{* *}$ & $0.83^{* *}$ & $0.90^{* *}$ & $0.96^{* *}$ & $0.67^{*}$ & $0.82^{* *}$ & $0.73^{*}$ & $0.75^{*}$ & $0.58^{*}$ & $0.57^{*}$ \\
\hline PRC & $0.56^{*}$ & 0.00 & 0.03 & $0.98^{* *}$ & $0.99^{* *}$ & $0.80^{* *}$ & $0.97^{* *}$ & 0.01 & 0.02 & 0.08 \\
\hline SNOW & 0.24 & 0.00 & 0.05 & 0.38 & 0.39 & 0.32 & 0.39 & 0.00 & 0.02 & 0.07 \\
\hline SSUP & 0.07 & 0.00 & 0.01 & 0.03 & 0.04 & 0.04 & 0.03 & 0.07 & 0.03 & 0.03 \\
\hline
\end{tabular}




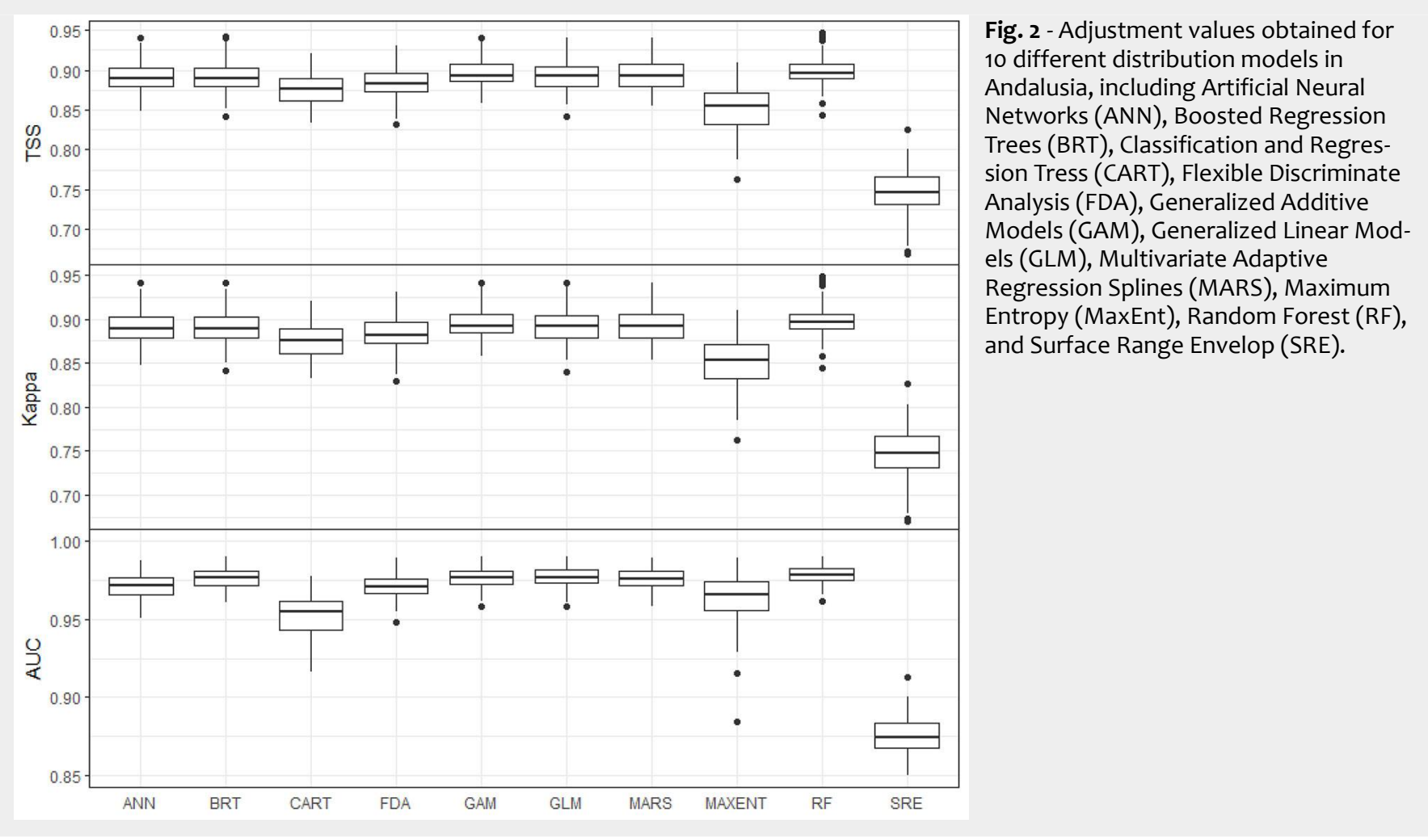

other hand, it is interesting to note that the models, in general, presented higher correlations (Tab. 3). The classification (BRT, CART, and RF) and regression method (GAM and GLM) predictions were highly correlated with each other. More- over, ANN, FDA, and MARS presented acceptable correlations with the rest of the models (Tab. 4).

All ensemble models presented TSS $>0.77$, Kappa> 0.90, and AUC > 0.98, the ensemble models committee averaging (CA) and probability mean weight decay (WD) being the best ones (Tab. 4). In this table, we have excluded the results corresponding to the ensemble models in accordance with the coefficient of variance result appearing in Fig. 3, with variability between all model

Tab. 3 - Pearson's correlation matrix of the concordance of the different spatial distribution models analyzed: Generalized Linear Models (GLM), Generalized Additive Models (GAM), Classification and Regression Trees (CART), Flexible Discriminate Analysis (FDA), Artificial Neural Networks (ANN), Multivariate Adaptive Regression Splines (MARS), Maximum Entropy Modelling (MaxEnt), Random Forest (RF) and Boosted Regression Trees (BRT) and one similar to BIOCLIM, Surface Range Envelop (SRE). All correlation were significant with $\mathrm{p}<0.001$ (2-tailed).

\begin{tabular}{lcccccccccc}
\hline Model & ANN & BRT & CART & FDA & GAM & GLM & MARS & MaxEnt & RF & SRE \\
\hline ANN & 1.000 & - & - & - & - & - & - & - & - & - \\
BRT & 0.885 & 1.000 & - & - & - & - & - & - & - & - \\
CART & 0.843 & 0.966 & 1.000 & - & - & - & - & - & - & - \\
FDA & 0.890 & 0.888 & 0.865 & 1.000 & - & - & - & - & - & - \\
GAM & 0.920 & 0.832 & 0.782 & 0.856 & 1.000 & - & - & - & - & - \\
GLM & 0.891 & 0.878 & 0.841 & 0.862 & 0.971 & 1.000 & - & - & - & - \\
MARS & 0.831 & 0.876 & 0.828 & 0.844 & 0.873 & 0.875 & 1.000 & - & - & - \\
MaxEnt & 0.821 & 0.881 & 0.856 & 0.751 & 0.762 & 0.799 & 0.872 & 1.000 & - & - \\
RF & 0.921 & 0.950 & 0.912 & 0.867 & 0.851 & 0.889 & 0.889 & 0.801 & 1.000 & - \\
SRE & 0.603 & 0.666 & 0.651 & 0.623 & 0.588 & 0.601 & 0.620 & 0.685 & 0.642 & 1.000 \\
\hline
\end{tabular}

Tab. 4 - Adjustment values obtained with the ensemble models of Pinus nigra habitat prediction in Andalusia: Cohen's Kappa, Area Under the Curve (AUC), True Skills Statistic (TSS), sensitivity (true positive rate), and specificity (true negative rate).

\begin{tabular}{lcccccc}
\hline Ensemble model & Kappa & TSS & AUC & Sensitivity & Specificity & Threshold \\
\hline Mean & 0.786 & 0.904 & 0.986 & 0.9725 & 0.9313 & 0.869 \\
Lower Confident interval & 0.786 & 0.904 & 0.986 & 0.9714 & 0.9332 & 0.846 \\
Upper Confident interval & 0.784 & 0.904 & 0.986 & 0.9735 & 0.9311 & 0.881 \\
Median & 0.774 & 0.903 & 0.983 & 0.9724 & 0.9307 & 0.913 \\
Committee averaging & 0.802 & 0.905 & 0.987 & 0.9756 & 0.9298 & 0.800 \\
Probability mean weight decay & 0.786 & 0.904 & 0.986 & 0.9725 & 0.9319 & 0.806 \\
\hline
\end{tabular}


A)

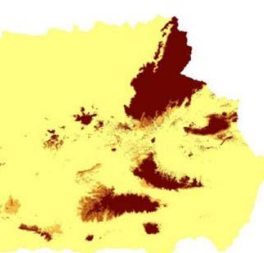

C)

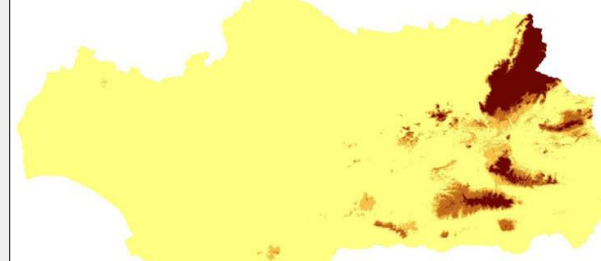

B)

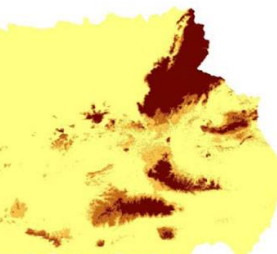

N Probabililty of occurence Pinus nigra

$\left\{\begin{array}{l}\square-75 \% \\ \square-25 \% \square\end{array}\right.$

D)
Fig. 3 - Present probability of occurrence of $P$. nigra subsp. salzmannii in Andalusia (Spain). Four ensemble model predictions are shown here: $(A)$ committee averaging; (B) mean; (C) probability mean weight decay; (D) coefficient of variation. predictions of below $25 \%$, which means that, mostly, all the models agree with the predictions. Pixels with a high coefficient of variance are recognized as being the uncertain pixels predicted.

Black pine present and future habitat suitability

The ensemble SDM of $P$. nigra subsp. salz- mannii in Andalusia predicted the highest probability of occurrence over the eastern areas (Sierra Cazorla, Sierra María, Sierra de Baza, and Sierra Nevada - Fig. 3), with a lesser presence in the mid-south (Sierra de las Nieves), which largely agrees with the current distribution of the species. The three ensemble models selected (CA, WD, and mean) showed a high degree of agree- ment in their predictions (Fig. 4). Sierra de Cazorla appears as the area with the highest $P$. nigra subsp. salzmannii occurrence within Andalusia, with a total surface area coverage of $50 \%$ (Fig. 3, see also Tab. S2 in Supplementary material) in its current prediction.

In the forecasted habitat suitability, the general probability of $P$. nigra subsp. salz-
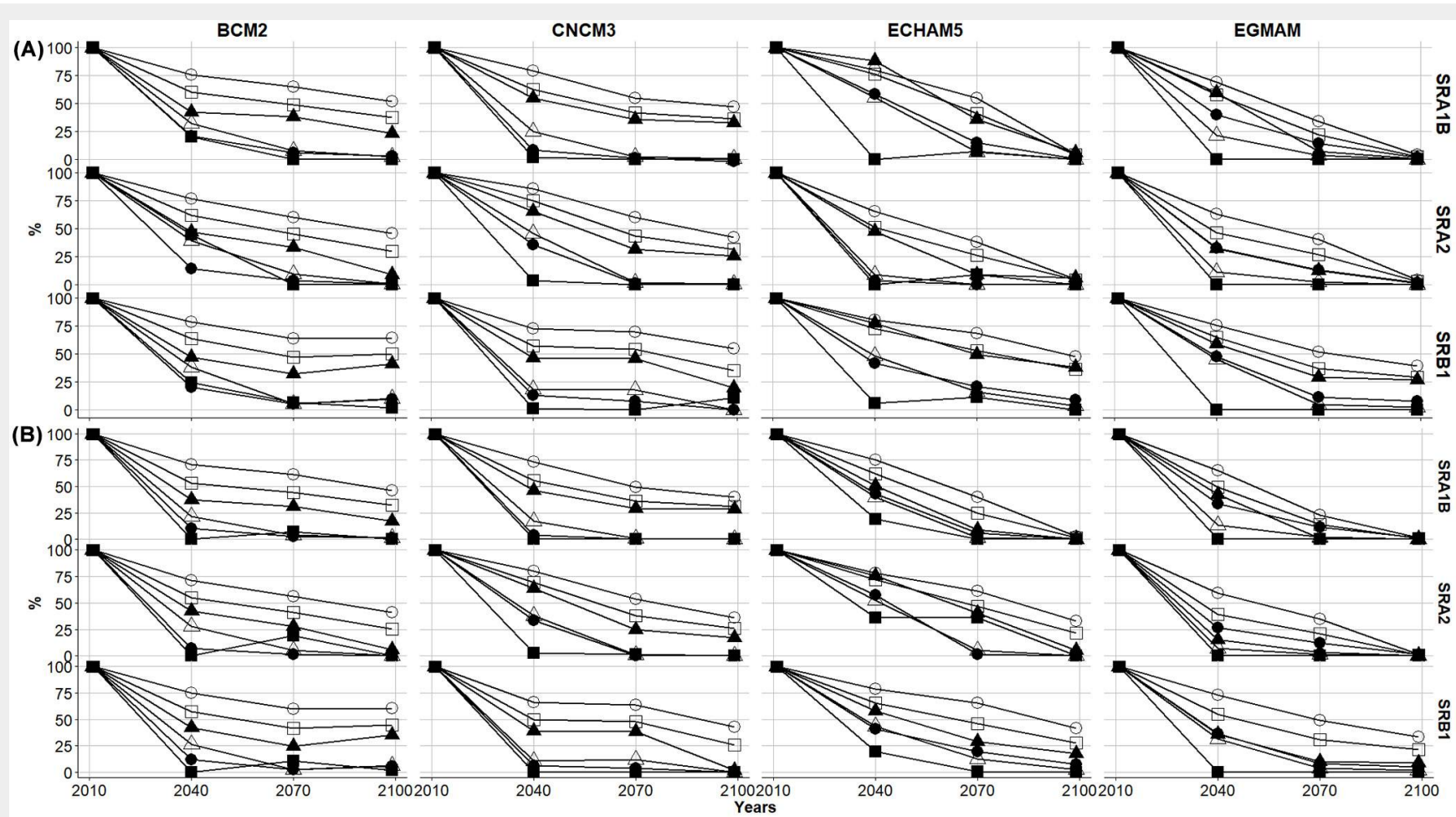

$\square$ Andalucia $\triangle$ S.Baza $\bullet$ S. Maria $O S$. Cazorla $\boldsymbol{Q}$ S. Nieves $\Delta$ S.Nevada

Fig. 4 - Percentage loss of the area of habitat suitability of P. nigra subsp. salzmannii under future projections (2040, 2070, and 2099): for different scenarios (SRA2, SRA1B, and SRB1), three Global Circulation Models (GCM: BCM2, CNCM3, and ECHAM5), and one Regional Circulation Model (EGMAM). Percentage of habitat suitability remaining in relation to the total present area of $P$. nigra subsp. salzmannii, predicted by the Probability Mean Weight Decay (WD) and Committee Averaging (CA) ensemble models. 
mannii occurrence in Andalusia widely decreases (Fig. 4, see also Tab. S2, Fig. S2 in Supplementary material), and the species is expected to lose habitat suitability at moderate altitudes, probably extending to higher ones as climate change proceeds (Fig. 4, Fig. S2). The southern areas (Sierra de las Nieves) disappear and the probability of species occurrence decreases, compared to the present predictions, for the eastern populations. Overall, all the populations showed a strong decrease in habitat suitability across the different scenarios (Fig. 4, Tab. S2 and Fig. S2 in Supplementary material). The predictions were significantly affected by the scenario, especially for longer periods of time (Fig. S2). The probability occurrence of $P$. nigra subsp. salzmannii will have diminished by nearly $70 \%$ on average by 2099 (Fig. 4, Tab. S2 and Fig. S2). It is worth mentioning that, potentially, Sierra de Cazorla will remain the most suitable area for $P$. nigra subsp. salzmannii growth, even under the most pessimistic scenarios.

The future predictions forecast a reduction in the potential habitat of $P$. nigra subsp. salzmannii, of 50\% in 2040 and $99 \%$ in 2099 (Tab. S2 and Fig. S2 in Supplementary material). These results varied depending on the GCM used and the scenario, while the ensemble modeling technique used had a minor effect. The more optimistic results predict a habitat suitability reduction close to $40 \%$ (BCM2, SRB1) by 2099, while others predict a loss of over 99\% (EGMAN, $\mathrm{SRA} 2$ ) in the same period. In general, the regional GCM (EGMAM) presented predictions more pessimistic than those of the intercontinental ones (Tab. S2 and Fig. S2). The most optimistic results were given by $\mathrm{CNCM}_{3}$ and $\mathrm{BCM}_{2}$; the potential area remaining exceeded $20 \%$ in some cases.

\section{Discussion}

Species distribution models are a simple yet efficient statistics-based method used to map the spatial range of species and to forecast climate change impacts on species ranges (Franklin 2010, Elith \& Franklin 2013). They have been used for many different purposes, including: conservation management, theory testing in biogeography and ecology, species management, and climate change impact assessment (Franklin 2010). In this work, we used an integrated model approach to assess the spatiotemporal patterns of suitable habitats for $P$. nigra subsp. salzmanni in the southern Iberian Peninsula, under four climate models. Biomod2 has shown the simplicity involved in the modelling, which enables its use for model distribution shifts resulting from climate change. In particular, our study constitutes a new approach with respect to other models previously used for predicting the distribution of the species (Attorre et al. 2011, López-Tirado \& Hidalgo 2014, Marchi et al. 2016), due to its focus on a relevant regional-scale design and on the populations most sensitive to climate change. One of the remarkable characteristics of our approach is the applicability of the results in biodiversity conservation and forest management (Hampe \& Petit 2005).

\section{Current potential habitat description}

The six main environmental variables used, listed in order of importance, were: NDF, PRC, IAR, SSUP, ETO, and SNOW (Tab. 1). NDF had the strongest influence on $P$. nigra distribution, in agreement with other studies that stressed the key role of low temperatures to explain the geographical distribution of $P$. nigra in Mediterranean areas (Gandullo \& Palomares 1994, ElenaRosselló \& Sánchez-Palomares 1991). P. nigra is benefited by an increase in the NDF, particularly in dry Mediterranean mountain areas, where it can compete with other coexisting coniferous species which are more sensitive to drought ( $P$. sylvestris and $P$. pinaster) or to low temperatures ( $P$. halepensis). This geographic distribution has traditionally been related to a relatively short vegetative period, high moisture, and a high degree of continentality (Elena-Rosselló \& Sánchez-Palomares 1991), as well as to variables that are negatively related to the minimum average temperature (Sanchez-Salguero et al. 2013). This agrees with the experimental findings of Gandullo \& Palomares (1994), who reported an optimal distribution for this species on northern slopes above $1000 \mathrm{~m}$ a.s.l., with mean annual temperatures ranging between 6.1 and $10.5^{\circ} \mathrm{C}$.

The dependence of $P$. nigra subsp. salzmannii on the annual precipitation shows its high sensitivity to annual and seasonal rainfall oscillations. The greatest potential suitability for the species has been reported in areas with annual rainfall of over $950 \mathrm{~mm}$, with minimum summer precipitation of over $25-30 \mathrm{~mm}$ (Gandullo \& Palomares 1994, López-Tirado \& Hidalgo 2014). Consequently, the species requires a certain degree of soil moisture, although it is also one of the few tree species that resists the most severe winter conditions (SNOW) in southern Spain as well as very dry summers (IAR), frequently found in Mediterranean high mountains supporting a snowpack as an important compensation feature for dry conditions. Under such conditions (mountain climate at high altitudes), P. nigra subsp. salzmannii is highly competitive and is one of the main forest species in the Mediterranean region (Herrero et al. 2013).

\section{Model selection}

The biomod2 software has been used to predict the habitat of forest species of different forms and parameterizations (Duque-Lazo et al. 2016). In this work, we have demonstrated differences in prediction performance between modeling methods at a regional scale. In general terms, the results agree with those obtained from the application of biomod2 to the prediction of the distribution of forest species at a local and regional scale (López-Tirado \& Hidalgo 2014). The linear methods (GLM and GAM) surpassed in accuracy the rest of the techniques used. Simple linear relationships using the selected climate variables and occurrence point locations could explain the highly specific habitat suitability of $P$. nigra subsp. salzmannii. The classification methods (BRT, CART, and RF), which are based on multiple data partitioning and increase the model's complexity, also gave accurate relationships, supporting the linear relationship between the habitat suitability of $P$. nigra and the environmental variables. The methods ANN, FDA, and MARS yielded accurate responses, although with a high variance; such responses might be due to chance or proper set data through crossvalidation. MaxEnt showed a surprisingly low predictive power and stability for the three statistics studied, despite being one of the most widely used modeling techniques and being able to build linear relationships between response and explanatory variables (Duque-Lazo et al. 2016). Finally, the power of SRE in the modelling of species distribution, in comparison with other methods, has been doubted. In this study, the used ensemble models differed in terms of future predictions, depending on the GCM studied. The ensemble model calculated by WD presented a higher overall total area for the current prediction than the ensemble modeling calculated by CA. Moreover, the percentage area loss was also higher for the ensemble model calculated by WD. These results could be due to an over-prediction of the current area, the difference being marked in the Sierra Nevada study area with 500 ha more in the ensemble model calculated by WD than for CA (Tab. 1, Tab. 2).

\section{Future habitat projection}

Recent studies have predicted a reduction in P. nigra subsp. salzmannii habitat suitability and tree growth in the next few decades in southern Europe (Sanchez-Salguero et al. 2012, López-Tirado \& Hidalgo 2014, Bede-Fazekas et al. 2014, Marchi et al. 2016), related to an increase in temperatures. Accordingly, our results suggest that winter temperatures and seasonal precipitation shape the distribution of $P$. nigra subsp. salzmannii in southern Spain (Camarero et al. 2013), and that shifts to higher altitudes rather than higher latitudes are expected in the future (Navarro-Cerrillo et al. 2014). Habitat models showed the sensitivity of this species to minimum temperatures and precipitation, in agreement with previous studies in the Mediterranean region indicating these as crucial factors determining, for example, Quercus ilex and Q. faginea forests (Felicísimo et al. 2011).

Our results suggest a dramatic reduction in locations representing a suitable habitat for $P$. nigra subsp. salzmannii due to climatic transitions: by $24.8 \%$ (ECHAM5-SRA2) to $52.9 \%$ (EGMAM-SRA1B) of the extent of 
their current distributions (as simulated for the present climate) in 2040, and by $55.5 \%$ (BCM2-SRB1) to <99\% (ECHAM5-SRA2, EG MAM-SRA2 and SRB1) in 2099 (Tab. 4). This trend, namely the loss of suitable habitats, was consistent among climate scenarios and populations.

Alternatively, the populations could ex tend northwards to central Spain in response to future conditions, and we as sumed here that the species fully achieves its potential changes in distribution (mean ing that we did not assume any dispersal limitation). That is, however, an unlikely and optimistic assumption. The fact that $P$. nigra subsp. salzmannii is a mountain species whose populations are highly isolated, with scant mountain ecosystems connecting the northern and central Iberian Peninsula populations with the southernmost ones, suggests that this scenario would be unlikely (Candel-Pérez et al. 2012). Therefore, $P$. nigra subsp. salzmannii may only persist in the long term as residual populations derived from its present distribution. Also, there is a great threat of local extinction, especially for those populations with a more restricted distribution (Sierra de Baza, Sierra de la Almijara, and Sierra de María - Camarero et al. 2013, Navarro-Cerrillo et al. 2014). Regarding altitude migration, although there are well-documented examples of populations migrating to altitudes higher than those at which they occur today as an apparent response to the ongoing climate change, the speed of that migration is much slower than would be needed to track the changing climate (Lenoir et al. 2008). In the case of P. nigra subsp. salzmannii in southern Spain, an up ward migration of 300-400 m would be required to compensate for the change in climate expected for the year 2040 as pre dicted, for instance, by the A2 scenario of the Canadian GCM (Candel-Pérez et al. 2012). Forest mortality may be an observable response to these changes, as sug gested by previous studies where dendrochronological and ecological data showed the critical and marginal situation of $P$. nigra subsp. salzmannii populations (Linares \& Tíscar 2010, Piermattei et al. 2012, Sanchez-Salguero et al. 2013).

However, projections of potential future distributions also need to be interpreted with caution. Even if the models presented in this study are quite accurate and are commonly used to assess the impact of global change (Thuiller 2014), we have not accounted here for biotic interactions that may modify habitat suitability. For exam ple, positive interactions with mycorrhizal fungi may enable trees to withstand drier conditions without any significant growth reduction (Collins Johnson et al. 2010). Fur thermore, trees are incredibly long-lived and resilient (Petit \& Hampe 2006) and therefore we can expect individuals to persist under sub-optimal conditions for long periods of time (Sanchez-Salguero et al. 2012), while waiting for infrequent benign conditions to be reproduced. Therefore, an important aspect that must be considered is forest monitoring. Currently, only time and empirical data will give us a real idea about the reliability of such models (Kautz et al. 2017).

Our results have serious implications for species adaptation and forest management (Camarero et al. 2013, Sanchez-Salguero et al. 2013). If this is coupled with the loss of a critical stopover site, the results for $P$. nigra subsp. salzmannii populations in southern Spain might be catastrophic. Some populations, of course, may be able to migrate (Sierra de Cazorla) to higher latitudes or altitudes in the face of climate change; but other populations would seem to face local extinction. The Sierra de Cazorla populations showed the greatest overlap between the potential and future suitable distributions, highlighting this area as a key genetic resource for the in situ conservation of $P$. nigra forests in the southern Mediterranean region (Tíscar \& Lucas-Borja 2016)

\section{Conclusion}

Given the accumulating evidence of recent climate changes, an evaluation of the current and future distributions of $P$. nigra subsp. salzmannii in Andalusia (southern Spain) is described in this paper. This information is necessary to ensure that the most threatened populations of such species will be afforded protection in response to climate change, by adjusting their protection status and forest management. Our results show an important contraction of the distribution area for all GCM models, with a minimum potential reduction of $40 \%(B C M 2, S R B 1)$ in 2099. The changing climate will inevitably result in impacts on biomes and community structures. Thus, its mitigation, as well as adaptation to potential future scenarios, is vital to the conservation of climate-sensitive species. Future research that combines bioclimatic niche modeling with a mechanistic disturbance, dispersal, and competition model will be likely to provide a greater insight into the potential range of $P$. nigra subsp. salzmannii in the face of climate change. Furthermore, it would supply information that influenced forest management options and restoration - that may include ecological restoration, selected thinning, or assisted migration. Some alternatives would ensure "fine-grained" landscapes with patches of a diverse range of semi-natural habitats - including woodlands, heathlands, and shrubs - that offered suitable habitat niches to sustain distribution responses to changing environmental conditions. Additionally, the distribution of protected areas should be revised to include extensive areas of natural or semi-natural habitats of coniferous Mediterranean forests, in particular plantations such as artificial $P$. nigra subsp. salzmannii forests, which offer a diverse range of physical habitats.

\section{Acknowledgements}

We acknowledge the financial support of ESPECTRAMED (CGL2017-86161-R), University of Córdoba - Campus de Excelencia $\mathrm{CEIA}_{3}$, and AEMET (Agencia Estatal de Meteorologia) for providing meteorological data. R. Sánchez-Salguero has been supported by a postdoctoral fellowship (FEDER - Programa de Fortalecimiento en $I+D+i$ de las Universidades 2014-2015 de la Junta de Andalucía) and the "CoMo-ReAdapt" Spanish project (CGL2013-48843-C2-1-R). The authors also thank Dr. Miguel B. Araujo for his valuable comments at the beginning of this work.

\section{Authors' contributions}

RMNC conceived the study, analyzed data, performed research, and wrote the paper; JDL analyzed data and contributed new methods; RDM conceived the study and performed research; RSS and GPR wrote the paper.

\section{References}

Allouche O, Tsoar A, Kadmon R (2006). Assessing the accuracy of species distribution models: prevalence, kappa and the true skill statistic (TSS). Journal of Applied Ecology 43: 1223-1232. - doi: 10.1111/j.1365-2664.2006.01214.x

Araújo MB, New M (2007). Ensemble forecasting of species distributions. Trends in Ecology and Evolution 22: 42-47. - doi: 10.1016/j.tree.2006.09. 010

Attorre F, Alfò M, De Sanctis M, Francesconi F, Valenti R, Vitale M, Bruno F (2011). Evaluating the effects of climate change on tree species abundance and distribution in the Italian peninsula. Applied Vegetation Science 14 (2): 242-255. doi: 10.1111/j.1654-109X.2010.01114.x

Badeau V, Dupouey JL, Cluzeau C, Drapier JS, Le Bas C (2010). Climate change and the biogeography of French tree species: first results and perspectives. In: "Forests, Carbon Cycle and Climate Change" (Loustau D ed). Edition Quae, Collection Update Sciences and Technology, Paris, France, pp. 231-252. [online] URL: http:// books.google.com/books?id=6bMiCWAAQBAJ Barbet-Massin $\mathrm{M}$, Jiguet F, Albert $\mathrm{CH}$, Thuiller W (2012). Selecting pseudo-absences for species distribution models: how, where and how many? Methods in ecology and evolution 3 (2): 327-338. - doi: 10.1111/j.2041-210X.2011.00172.x Bede-Fazekas A, Horvath L, Kocsis M (2014). Impact of climate change on the potential distribution of Mediterranean pines. Idojaras 118: 4152. [online] URL: http://unipub.lib.uni-corvinus. hu/1511/

Benito Garzón M, Sánchez De Dios R, Sainz Ollero $H$ (2008). Effects of climate change on the distribution of Iberian tree species. Applied Vegetation Science 11: 169-178. - doi: 10.3170/20 08-7-18348

Camarero JJ, Manzanedo R, Sanchez-Salguero R, Navarro-Cerrillo R (2013). Growth response to climate and drought change along an aridity gradient in the southernmost Pinus nigra relict forests. Annals of Forest Science 70: 769-780. doi: 10.1007/s13595-013-0321-9

Candel-Pérez D, Linares JC, Viñegla B, LucasBorja ME (2012). Assessing climate-growth rela- 
tionships under contrasting stands of co-occurring Iberian pines along an altitudinal gradient. Forest Ecology and Management 274: 48-57. doi: 10.1016/j.foreco.2012.02.010

Cohen J (1960). A coefficient of agreement for nominal scales. Educational and Psychological Measurement 20: 37-46. - doi: 10.1177/0013164 46002000104

Collins Johnson N, Wilson GW, Bowker MA, Wilson JA, Miller R (2010). Resource limitation is a driver of local adaptation in mycorrhizal symbioses. Proceedings of the National Academy of Sciences USA 107: 2093-2098. - doi: 10.1073/ pnas.0906710107

Duque-Lazo J, Van Gils H, Groen TA, Navarro-Cerrillo RM (2016). Transferability of species distribution models: the case of Phytophthora cinnamomi in Southwest Spain and Southwest Australia. Ecological Modelling 320: 62-70. - doi: 10.1016/j.ecolmodel.2015.09.019

Elena-Rosselló R, Sánchez-Palomares O (1991). Los pinares españoles de Pinus nigra: síntesis ecológica [The Spanish pine forests of Pinus nigra: ecological synthesis]. INIA, Madrid, Spain, pp. 110. [in Spanish]

Elith J, Franklin J (2013). Species distribution modeling. In: "Encyclopedia of Biodiversity ( $2^{\text {nd }}$ edn)" (Simon AL eds). Academic Press, Waltham, MS, USA, pp. 692-705.

Felicísimo AM, Muñoz J, Villalba CJ, Mateo RG (2011). Impactos, vulnerabilidad y adaptación al cambio climático de la biodiversidad española: proyecciones de las áreas de distribución potencial de la flora amenazada y las especies forestales de la España peninsular con efecto del cambio climático [Impacts, vulnerability and adaptation to climate change of Spanish biodiversity: projections of the areas of potential distribution of threatened flora and forest species in peninsular Spain with the effect of climate change]. Oficina Española de Cambio Climático, Ministerio de Medio Ambiente y Medio Rural y Marino, Madrid, Spain, pp. 552. [in Spanish]

Franklin J (2010). Mapping species distributions: spatial inference and prediction. Cambridge University Press, New York, USA, pp. 319. [online] URL: http://books.google.com/books? id $=$ CkshAwAAQBAJ

Gandullo JM, Palomares OS (1994). Estaciones ecológicas de los pinares españoles [Ecological sites of the Spanish pine forests]. ICONA, Madrid, Spain, pp. 188. [in Spanish].

García-Valdés R, Zavala MA, Araújo MB, Purves DW (2013). Chasing a moving target: projecting climate change-induced shifts in non-equilibrial tree species distributions. Journal of Ecology 101: 441-453. - doi: 10.1111/1365-2745.12049

Giorgi F (2006). Climate change hot-spots. Geophysical Research Letters 33 (8): 89. - doi: 10.1029/2006GL025734

Hampe A, Petit RJ (2005). Conserving biodiversity under climate change: the rear edge matters. Ecology Letters 8: 461-467. - doi: 10.1111/j. 1461-0248.2005.00739.x

Herrero A, Rigling A, Zamora R (2013). Varying climate sensitivity at the dry distribution edge of Pinus sylvestris and P. nigra. Forest Ecology and Management 308: 50-61. - doi: 10.1016/j.for eco.2013.07.034

IPCC (2014). Climate change (2014): impacts, adaptation, and vulnerability. Part A: global and sectoral aspects. Contribution of Working Group II to the Fifth Assessment Report of the Intergovernmental Panel on Climate Change (Field CB, Barros VR, Dokken DJ, Mach KJ, Mastrandrea MD, Bilir TE, Chatterjee M, Ebi KL, Estrada YO, Genova RC, Girma B, Kissel ES, Levy AN, MacCracken S, Mastrandrea PR, White LL eds). Cambridge University Press, Cambridge, UK and New York, NY, USA, pp. 1132.

Kautz M, Meddens AJ, Hall RJ, Arneth A (2017). Biotic disturbances in Northern Hemisphere forests-a synthesis of recent data, uncertainties and implications for forest monitoring and modelling. Global Ecology and Biogeography 26 (5): 533-552. - doi: 10.1111/geb.12558

Lenoir J, Gégout JC, Marquet PA, De Ruffray P, Brisse $H$ (2008). A significant upward shift in plant species optimum elevation during the $20^{\text {th }}$ century. Science 320: 1768-1771. - doi: 10.1126/ science. 1156831

Linares JC, Tíscar PA (2010). Climate change im pacts and vulnerability of the southern populations of Pinus nigra subsp. salzmannii. Tree Physiology 30: 795-806. - doi: 10.1093/treephys/ tpq052

López-Tirado J, Hidalgo PJ (2014). A high resolution predictive model for relict trees in the Mediterranean-mountain forests (Pinus sylvestris L., P. nigra Arnold and Abies pinsapo Boiss.) from the south of Spain: a reliable management tool for reforestation. Forest Ecology and Management 330: 105-114. - doi: 10.1016/j.for eco.2014.07.009

Madrigal-González J, Zavala MA (2014). Competition and tree age modulated last century pine growth responses to high frequency of dry years in a water limited forest ecosystem. Agricultural and Forest Meteorology 192-193: 18-26. doi: 10.1016/j.agrformet.2014.02.011

Marchi M, Nocentini S, Ducci F (2016). Future scenarios and conservation strategies for a rear-edge marginal population of Pinus nigra Arnold in Italian central Apennines. Forest Systems 25 (3): e072. - doi: 10.5424/fs/201625309476

Merow C, Smith MJ, Edwards TC, Guisan A, McMahon SM, Normand S, Thuiller W, Wüest RO, Zimmermann NE, Elith J (2014). What do we gain from simplicity versus complexity in species distribution models? Ecography 37 : 1267-1281. - doi: 10.1111/ecog.00845

Mod HK, Scherrer D, Luoto M, Guisan A (2016). What we use is not what we know: environmental predictors in plant distribution models. Journal of Vegetation Science 27 (6): 1308-1322. doi: $10.1111 /$ jvs.12444

Navarro-Cerrillo RM, Hernandez-Bermejo JE, Hernandez-Clemente R (2011). Evaluating models to assess the distribution of Buxus balearica in southern Spain. Applied Vegetation Science 14: 256-267. - doi: 10.1111/j.1654-109X.2010.0111 2.x

Navarro-Cerrillo RM, Sánchez-Salguero R, Manzanedo RD, Camarero JJ, Fernández-Cancio A (2014). Site and age condition the growth responses to climate and drought of relict Pinus nigra subsp. salzmannii populations in Southern Spain. Tree-Ring Research 70: 145-155. - doi: 10.3959/1536-1098-70.2.145

Petit RJ, Hampe A (2006). Some evolutionary consequences of being a tree. Annual Review of Ecology Evolution and Systematics 37: 187214. - doi: 10.1146/annurev.ecolsys.37.091305.110 215

Piermattei A, Renzaglia F, Urbinati C (2012). Recent expansion of Pinus nigra Arn. above the timberline in the central Apennines, Italy. Annals of Forest Science 69: 509-517. - doi: 10.1007 /s13595-012-0207-2

Porfirio LL, Harris RM, Lefroy E, Hugh S, Gould SF, Lee G, Bindoff NL, Mackey B (2014). Improving the use of species distribution models in conservation planning and management under climate change. PLoS ONE 9 (11): e113749. - doi: 10.1371/journal.pone.0113749

Pyšek P, Manceur AM, Alba C, McGregor KF, Pergl J, Chytry M, Danihelka J, Kartesz J, Klimešová J, Lučanová $M$, Moravcová L, Nishino M, Sádlo J, Suda J, Tichy L, Kühn I (2014). Naturalization of central Iberian plants in North America: species traits, habitats, propagule pressure, residence time. Ecology 96 (3): 762774.

Quinn GG, Keough MJ (2002). Experimental design and data analysis for biologists. Cambridge University Press, Cambridge, UK, pp. 553. - doi: $10.1017 / C B O 9780511806384$

R Core Development Team (2014). R: a language and environment for statistical computing. $R$ Foundation for Statistical Computing. R Foundation for Statistical Computing, Vienna, Austria. [online] URL: http://www.r-project.org

REDIAM (2010). Andalusian Regional Government database. Web site. [online] URL: http:// www.juntadeandalucia.es/medioambiente/site/ rediam

Sanchez-Salguero R, Navarro-Cerrillo RM, Swetnam TW, Zavala MA (2012). Is drought the main decline factor at the rear edge of Europe? The case of southern Iberian pine plantations. Forest Ecology and Management 271: 158-169. doi: 10.1016/j.foreco.2012.01.040

Sanchez-Salguero R, Camarero JJ, Dobbertin M, Fernández-Cancio A, Vilà-Cabrera A, Manzanedo RD, Zavala MA, Navarro-Cerrillo RM (2013). Contrasting vulnerability and resilience to drought-induced decline of densely planted $v$ s. natural rear-edge Pinus nigra forests. Forest Ecology and Management 310: 956-967. - doi: 10.1016/j.foreco.2013.09.050

Soto A, Robledo-Arnuncio JJ, González-Martínez SC, Smouse PE, Alía R (2010). Climatic niche and neutral genetic diversity of the six Iberian pine species: a retrospective and prospective view. Molecular Ecology 19: 1396-1409. - doi: 10.1111/j. 1365-294X.2010.04571.X

Svenning JC, Skov F (2007). Could the tree diversity pattern in Europe be generated by postglacial dispersal limitation? Ecology Letters 10: 453-460. - doi: 10.1111/j.1461-0248.2007.01038.x

Syphard AD, Franklin J (2009). Differences in spatial predictions among species distribution modeling methods vary with species traits and environmental predictors. Ecography 32: 907918. - doi: 10.1111/j.1600-0587.2009.05883.x

Thuiller W (2014). Editorial commentary on "Patterns and uncertainties of species' range shifts under climate change". Global Ecology and Biogeography 20: 3593-3594. - doi: 10.1111/gcb.127 28

Thuiller W, Georges D, Engler R (2013). biomod2: 
ensemble platform for species distribution modeling. R package version 2.0.3/r539. [online] URL: http://cran.r-project.org/web/packa ges/biomod2/biomod2.pdf

Tíscar PA, Lucas-Borja ME (2016). Structure of old-growth and managed stands and growth of old trees in a Mediterranean Pinus nigra forest in southern Spain. Forestry 89 (2): 201-207. doi: 10.1093/forestry/cpwoo2

Vale CG, Tarroso P, Brito JC (2014). Predicting species distribution at range margins: testing the effects of study area extent, resolution and threshold selection in the Sahara-Sahel transition zone. Diversity and Distributions 20: 20-33. - doi: 10.1111/ddi.12115

Van Gils H, Conti F, Ciaschetti G, Westinga E (2012). Fine resolution distribution modelling of endemics in Majella National Park, Central Italy. Plant Biosystems 146: 276-287. - doi: 10.1080/112 63504.2012.685194
Villanueva JA (2005). Tercer inventario forestal nacional (1997-2007) [Third national forest inventory (1997-2007)]. Ministerio de Medio Ambiente y Medio Rural y Marino. Madrid, Spain, pp. 305. [in Spanish]

Zhang L, Liu S, Sun P, Wang T, Wang G, Zhang X, Wang $L$ (2015). Consensus forecasting of species distributions: the effects of niche model performance and niche properties. PLoS ONE 10 (3): e0120056. - doi: 10.1371/journal.pone.012 0056

\section{Supplementary Material}

Tab. S1 - Environmental data used for the habitat prediction of $P$. nigra subsp. salzmannii occurrence in Andalusia (Spain).

Tab. S2 - Total (ha) and percentage (in parentheses) area loss, relative to the values for 1961-2000, of Pinus nigra future projections (2040, 2070, and 2099) with different scenarios (SRA2, SRA1B, and SRB1), three Global Circulation Models (GCM: BCM2, $\mathrm{CNCM}_{3}, \mathrm{ECHAM} 5$ ), and one Regional Circulation Model (EGMAM).

Fig. S1 - Iberian (a), Spanish (b), and Andalusian (c) distribution of $P$. nigra subsp. salzmannii.

Fig. S2 - Future P. nigra subsp. salzmannii probability of occurrence prediction obtained by probability mean weight decay ensemble modeling with the Global Circulation Model EGMAM, the scenarios SRA2, $S R B 1$, and SRA1B, and the future projections 2040, 2070, and 2099.

Link: Navarro-Cerrillo_2588@supplo01.pdf 